\title{
Lekovi koji se koriste u akutnom koronarnom sindromu
}

\author{
Branka Terzić, Jelena Stepanović \\ Klinika za kardiologiju, Klinički centar Srbije; Medicinski fakultet, Univerzitet u Beogradu
}

\section{Aspirin}

Pri sumnji na AIM, bolesniku treba odmah dati aspirin u dozi od 150-300 mg da sažvaće, po mogućstvu oblik koji nije gastrorezistentan. Nakon toga, aspirin u dozi od $100 \mathrm{mg}$ na dan treba nastaviti kao dugotrajnu terapiju, izuzev u slučaju jasnih kontraindikacija (alergija na aspirin, gastrično krvarenje posle upotrebe aspirina). Aspirin je indikovan u svim kliničkim prezentacijama ishemijske bolesti srca, kao i u nemoj ishemiji (Tabela 1).

\section{Derivati tienopiridina}

\subsection{Klopidogrel}

Klopidogrel je antitrombocitni lek koji se u jetri metaboliše u aktivni oblik. Zbog toga se kod bolesnika u pPCl primenjuje doza opterećenja od $600 \mathrm{mg}$ da bi se brže dostigla visoka koncentracija leka. Treba nastaviti dnevnu dozu klopidogrela od 75 mg/dan (Tabela 1). Rezistencija na klopidogrel je posledica smanjene količine enzima CYP 2C19 u jetri odgovornih za metaboličku konverziju klopidogrela u aktivnu formu leka. Ustanovljeni su laboratorijski testovi za ispitivanje genski uslovljene rezistencije na klopidogrel koja se javlja kod 2-14\% ljudi. Kod bolesnika sa STEMI lečenih fibrinolitičkom terapijom, pored aspirina, potrebno je dati i klopidogrel u dozi opterećenja od $300 \mathrm{mg}$, a za starije od 75 godina, zbog rizika od krvarenja dozu od $75 \mathrm{mg}$. Klopidogrel se dalje primenjuje paralelno sa aspirinom u dozi od $75 \mathrm{mg} / \mathrm{dan}$, najkraće 12 meseci.

\subsection{Tiklopidin}

Tiklopidin je prvi antitrombocitni lek, derivat tienopiridina. Zamenjen je klopidogrelom zbog toga što češće od klopidogrela izaziva neželjene reakcije kao što su leukopenija, neutropenija i trombocitopenija. Većina bolesnika koja ispoljava rezistenciju na klopidogrel ima dobar antitrombocitini efekat na tiklopidin. Dnevna doza tiklopidina je $2 \times 250 \mathrm{mg}$. U toku prva 3 meseca terapije tiklopidinom potrebna je kontrola krvne slike zbog rizika od leukopenije i/ili neutropenije. Poremećaji u krvnoj slici su reverzibilni i posle prekida terapije tiklopidinom dolazi do oporavka. Dužina terapije je kao i za klopidogrel.

\subsection{Prasugrel}

Za razliku od ostalih derivata tienopiridina, prasugre izaziva brži, stabilniji i izraženiji antitrombocitni efekat. U poređenju sa klopidogrelom, efekat prasugrela nasta- je brže i pouzdaniji je. Doze: 60 mg je doza opterećenja, a zatim $10 \mathrm{mg} /$ dan. Zbog rizika od krvarenja treba izbegavati primenu kod starijih od 75 godina, zatim kada postoji visok rizik od krvarenja (ulkus, oralni antikoagulansi, fibrinolitici, hronična primena NAIL). Kod osoba lakših od $60 \mathrm{~kg}$ doza održavanja je $5 \mathrm{mg} / \mathrm{dan}$.

\subsection{Tikagrelor}

Tikagrelor je nukleozidni analog, antagonist ADP receptora na trombocitima kao i tienopiridini. Tikagrelor predstavlja aktivnu formu leka (nije potrebna njegova metabolička transformacija u jetri) i zato ispoljava brži antitrombocitni efekat koji je reverzibilan. Trombocite koje je inhibirao postaju aktivni posle nekoliko dana, za razliku od tienopiridina gde su ti trombociti isključeni iz funkcije u toku njihovog životnog veka, tj potrebno je stvaranje novih trombocita. Doza opterećenja je 180 $\mathrm{mg}$, a na dalje $2 \times 90 \mathrm{mg} / \mathrm{dan}$.

\section{Antagonisti glikoproteinskih Ilb/ Illa receptora}

Izgleda da je efikasnost i bezbednost antagonista GP IIb/ Illa najveća kada se primenjuju tokom PCl.

\subsection{Abciximab}

Abciximab je ukršteno mišje/humano monoklonsko antitelo, koje se vezuje za glikoprotenski IIb/IIla receptor na trombocitima i veoma moćno inhibiše agregaciju trombocita. Abciximab se primenjuje sa aspirinom i heparinom. Doze: pre početka PCI, IV bolus 0,25 mg za 10-60 minuta, a zatim kontinuirana IV infuzija u dozi od $0.125 \mu \mathrm{g} / \mathrm{kg} / \mathrm{min}$ (max. $10 \mu \mathrm{g} / \mathrm{min}$ ) u toku $12 \mathrm{~h}$ (Tabela 1).

\subsection{Tirofiban}

Tirofiban treba primenjivati samo kod bolesnika sa IBS i visokim rizikom pri $\mathrm{PCl}$, posebno kod bolesnika sa NSTEMI (Tabela 1). Tirofiban se daje u toku $30 \mathrm{~min} \mathrm{u}$ dozi od 0,4 $\mu \mathrm{g} / \mathrm{kg} / \mathrm{min}$, a zatim 0,1 $\mu \mathrm{g} / \mathrm{kg} / \mathrm{min} 12-24 \mathrm{~h}$.

\section{Antikoagulantni lekovi}

\subsection{Heparin}

Antikoagulantni lekovi se primenjuju kod svih bolesnika sa AKS (STEMI, NSTEMI, NAP) istovremeno sa antitrombocitnim lekovima. Nefrakcionisani heparin (UFH) se daje intravenski u bolusu u dozi od $60 \mathrm{j} / \mathrm{kg}$ (bolus od 5000 ij za bolesnike >65kg; iv bolus od 4000 ij za bole- 
snika <65 kg), i infuzija $12 \mathrm{j} / \mathrm{kg}$, maksimalno do $1000 \mathrm{j} / \mathrm{h}$ uz kontrolu aPTT, koje treba da bude 50-70s (ili ACT 250-350s, a zajedno sa antagonistima GP IIb/IIla 200250s). Nastaviti infuziju heparina do dolaska u salu (uz kontrolu aPTT-a). Kod bolesnika sa AIM i pPCI ne treba rutinski nastavljati heparin, osim kod bolesnika sa aneurzmom leve komore sa tromba, ili bez njega, kod AF, produžene vezanosti za postelju, odloženog uklanjanja uvodnika ili prethodno prisutnih indikacija za oralnu antikoagulantnu terapiju. Ne treba menjati nefrakcionisani heparin sa frakcionisanim i obrnuto zbog rizika od hemoragijskih komplikacija. U slučaju krvarenja ili predoziranja heparina, antidot je protamin sulfat $(1 \mathrm{mg}$ protamina neutrališe 80-100 ij heparina, ili prema vrednosti aPTT ili ACT). Protamin sulfat se daje sporo intravenski 5 $\mathrm{mg}$ u minuti, do maksimalne doze od $50 \mathrm{mg}$.

\subsection{Nisko molekulski heparini (LMWH)}

Enoksaparin se daje u dozi $1 \mathrm{mg} / \mathrm{kg}$ s.c. na $12 \mathrm{~h}$ za prevenciju ishemijskih komplikacija u NAP i NSTEMI. Terapija enoksaparinom može da se započne i.v. bolusom u dozi od $0,3 \mathrm{mg} / \mathrm{kg}$ u STEMI, a zatim potkožno. Za bolesnike sa bubrežnom insuficijencijom i za starije od 75 godina doza enoksaparina je $0,75 \mathrm{mg} / \mathrm{kg}$ s.c., bez i.v. bolusa. Antidot za LMWH je protamin sulfat: $1 \mathrm{mg}$ protamina neutrališe $100 \mathrm{ij} \mathrm{LMWH.} \mathrm{Daje} \mathrm{se} \mathrm{i.v.} \mathrm{intermitentno}$ brzinom od $5 \mathrm{mg}$ u minuti, ili u sporoj infuziju do maksimalne doze od 25 do $50 \mathrm{mg}$.

Dalteparin: doza $120 \mathrm{~J} / \mathrm{kg}$ na $12 \mathrm{~h}$

Nadroparin: doza 86J/kg na $12 \mathrm{~h}$

\subsection{Bivalirudin}

Bivalirudin je sintetski polipetid, analog hirudina (prirodni antikoagulans izolovan iz pijavica), direktni inhibitor trombina. Ima brz i pouzdan antikoagulantni efekat, brzo se eliminiše iz organizma. Bezbedan je i kod bolesnika koji na heparin dobiju HIT tip II. Kod bolesnika sa planiranom $\mathrm{PCl}$ procedurom daje se i.v. kao bolus $\mathrm{u}$ dozi od $0,1 \mathrm{mg} / \mathrm{kg}$, a zatim u infuziji $1,25 \mathrm{mg} / \mathrm{kg} / \mathrm{hr}$. Nema antidota.

\subsection{Fondaparin}

Fondaparin je sintetski pentsaharid, aktivni centar heparina koji inhibiše faktor Xa posredstvom antitrombina. Ne deluje direktno na trombin. Primenjuje se s.c. u dozi od 2,5 mg/dan, do PCl procedure. Nema antidota.

\section{Oralna antikoagulantna trerapija}

Oralna antikoagulantna terapija kod bolesnika sa dvojnom antitrombocitnom terapijom se preporučuje samo ako postoji paroksizmalna ili permanentna atrijalna fibrilacija (CHADS, skor $\geq 2$ ), tromb u levoj komori, kod prethodne embolije pluća i/ili tromboze dubokih vena, kod bolesnika sa veštačkim srčanim zaliscima. Potreban je oprez kod bolesnika sa dvojnom antitrombocitnom terapijom i indikacijama za produženu oralnu antikoagulantnu terapiju (treba izbegavati implantaciju DES-ova). Kod trojne terapije doza aspirina treba da bude niža od 100 $\mathrm{mg}$, a INR maksimalno 2-2,5. Treba sugerisati što je moguće kraću trojnu terapiju, uz češću kontrolu INR-a.

\section{Fibrinolitički lekovi}

Trombolitički lekovi se koriste radi rastvaranja okluzivnog tromba u infarktnoj arteriji kod bolesnika sa STEMI. Efikasnost trombolitičke terapije zavisi od starosti tromba, tako da je period od početka infarktnog bola do primene leka od bitnog uticaja na uspešnost reperfuzije. Smatra se da su fibrin specifični trombolitici (alteplaza i tenekteplaza) efikasniji. Posle fibrinolitika se daje infuzija heparina (1000 j/h, tako da aPTT bude $50-70 \mathrm{~s})$.

\subsection{Streptokinaza}

Doziranje: 1,5 MegaJ u i.v. infuziji za 30-60 min. Pri bržem davanju je moguća hipotenzija koja je najčešće prolazna. Retko je potrebno prekinuti infuziju i nastaviti je odmah po uspostavljanju hemodinamske stabilnosti. S obzirom na to da je streptokinaza bakterijskog pore$\mathrm{kla}$, moguće su febrilne i alergijske reakcije na lek. Zbog imunogenih svojstava od 5 dana do 12 meseci od primene leka, streptokinaza ne sme ponovo da se da istom bolesniku.

\subsection{Alteplaza}

Alteplaza je tkivni aktivator plazminogena. Doziranje: i.v. bolus u dozi od $15 \mathrm{mg}$, a zatim i.v. infuzija u dozi od $50 \mathrm{mg}$ za $30 \mathrm{~min}$, a zatim $35 \mathrm{mg}$ za sledećih 60 minuta (ubrzani protokol). Za bolesnike koji imaju telesnu masu $<67 \mathrm{~kg}$, u prvih 30 minuta infuzije, primenjuje se maksimalna doza od $0,75 \mathrm{mg} / \mathrm{kg}$ TM.

\subsection{Tenekteplaza}

Tenekteplaza je po mehanizmu dejstva i strukturno veoma slična alteplazi, ima duži poluživot u plazmi i može da se primeni u obliku i.v. bolusa prehospitalno. Nije indikovana za lečenje bolesnika sa STEMI nakon $6 \mathrm{~h}$ od početka simptoma. Doziranje: bolus od 0,5 mg/kg TM, maksimalno $50 \mathrm{mg}$ i.v, za nekoliko sekundi.

Kontraindikacije za fibrinolitičku terapiju su predstavljene u okviru akutnog koronarnog sindroma.

Neželjene reakcije fibrinolitika: s obzirom na mehanizam dejstva fibrinolitika, najznačajnije su hemoragijske komplikacije (gastrointestinumske, intrakranijumske, perikardne i retroperitoneumske).

\section{Terapija bola u ishemijskog bolesti srca}

Za lečenje jakog bola u AIM i NAP daje se i.v. morfin u dozi od 2-4-6 mg, u intervalima od 10 do 15 minuta do maksimalne doze od $1 \mathrm{mg} / \mathrm{kg}$ za nekoliko sati. Za redukciju bola se još koristi terapija kiseonikom, primena beta blokatora i i.v. nitroglicerina (aplikacija spreja nitroglicerola). Korisno je imati nalokson (antagonist morfina u slučaju respiratorne depresije).

\section{Primena kiseonika}

Nije potrebna rutinska primena kiseonika u IBS, značajna je za bolesnike sa edemom pluća i lošijom satriacijom kiseonika (SO2<90\%). Primenjuje se u količini od 2 do $4 \mathrm{l} / \mathrm{min}$ preko nazalnog katetera. 
Tabela 1. Antitrombinski lekovi u revaskularizacionim procedurama miokarda ${ }^{1}$

\begin{tabular}{|c|c|c|c|}
\hline \multicolumn{4}{|l|}{ Elektivne $\mathrm{PCl}$} \\
\hline Antitrombocitna terapija & & Klasa preporuke & Nivo dokaza \\
\hline & aspirin & 1 & B \\
\hline & klopidogrel & 1 & A \\
\hline & $\begin{array}{l}\text { klopidogrel - pretretman sa udarnom } \\
\text { dozom od } 300 \mathrm{mg}>6 \mathrm{~h} \text { pre } \mathrm{PCl} \text { (ili } 600 \\
\mathrm{mg}>2 \mathrm{~h} \text { pre) }\end{array}$ & 1 & C \\
\hline & $\begin{array}{l}\text { *GP IIb-IIla antagonisti (u slučaju kritič- } \\
\text { ne situacije) }\end{array}$ & Ila & $\mathrm{C}$ \\
\hline \multicolumn{4}{|l|}{ Antikoagulantna terapija } \\
\hline & nefrakcionisani heparin & 1 & C \\
\hline & enoksaparin & Ila & B \\
\hline \multicolumn{4}{|l|}{ NSTE-AKS } \\
\hline \multicolumn{4}{|l|}{ Antitrombocitna terapija } \\
\hline & aspirin & 1 & $\mathrm{C}$ \\
\hline & $\begin{array}{l}\text { klopidogrel (600 mg udarna doza što je } \\
\text { pre moguće) }\end{array}$ & 1 & C \\
\hline & klopidogrel (9-12 meseci nakon PCI) & 1 & B \\
\hline & prasugrel & Ila & B \\
\hline & tikagrelor & 1 & B \\
\hline & $\begin{array}{l}\text { * GP IIb-IIla antagonisti (kod bolesnika } \\
\text { sa dokazanim velikim opterećenjem } \\
\text { intrakoronarnim trombom) }\end{array}$ & & \\
\hline & $\begin{array}{l}\text { absiksimab (sa dvojnom antitrombocit- } \\
\text { nom terapijom) }\end{array}$ & I & B \\
\hline & tirofiban, eptifibatid & Ila & B \\
\hline & davanje GP IIb-IIIa antagonista unapred & III & B \\
\hline \multicolumn{4}{|l|}{ Antikoagulantna terapija } \\
\hline \multirow[t]{2}{*}{ veoma visok rizik za ishemiju } & $\begin{array}{l}\text { nefrakcionisani heparin (+GP IIb-IIla } \\
\text { antagonist) }\end{array}$ & I & $\mathrm{C}$ \\
\hline & bivalirudin (monoterapija) & 1 & B \\
\hline \multirow[t]{4}{*}{ srednji do visok rizik za ishemiju } & nefrakcionisani heparin & 1 & C \\
\hline & bivalirudin & $\mathrm{I}$ & B \\
\hline & fondaparinuks & 1 & B \\
\hline & enoksaparin & Ila & B \\
\hline \multirow[t]{2}{*}{ nizak rizik za ishemiju } & fondaparinuks & 1 & B \\
\hline & enoksaparin & Ila & B \\
\hline \multicolumn{4}{|l|}{ STEMI } \\
\hline \multicolumn{4}{|l|}{ Antitrombocitna terapija } \\
\hline & aspirin & $\mathrm{I}$ & B \\
\hline & $\begin{array}{l}\text { klopidogrel (600 mg udarna doza što je } \\
\text { pre moguće) }\end{array}$ & I & C \\
\hline & prasugrel & $\mathrm{I}$ & B \\
\hline & tikagrelor & 1 & $\mathrm{~B}$ \\
\hline & $\begin{array}{l}\text { * GP IIb-IIla antagonisti (kod bolesnika } \\
\text { sa dokazanim velikim opterećenjem } \\
\text { intrakoronarnim trombom) }\end{array}$ & & \\
\hline & absiksimab & Ila & A \\
\hline & eptifibatid & Ila & B \\
\hline & tirofiban & $\mathrm{Ilb}$ & $\mathrm{B}$ \\
\hline & davanje GP IIb-IIIa antagonista unapred & III & $\mathrm{B}$ \\
\hline \multicolumn{4}{|l|}{ Antikoagulantna terapija } \\
\hline & bivalirudin (monoterapija) & 1 & B \\
\hline & nefrakcionisani heparin & $\mathrm{I}$ & C \\
\hline & fondaparinuks & III & B \\
\hline
\end{tabular}




\section{Beta blokatori}

Primena $\beta$-blokatora u AIM se započinje u akutnoj fazi, a zatim se nastavlja dugotrajna terapija, osim u slučaju postojanja kontraindikacija. Svi bolesnici posle AIM treba da dobiju dugotrajnu terapiju beta blokatorima ukoliko nema kontraindikacija (klasa preporuke I, nivo dokaza A). Neželjena dejstva $\beta$-blokatora: srčana insuficijencija, bronhospazam, bradikardija, hipotenzija.

\section{Nitroglicerol}

Prva upotreba nitroglicerola je bila sublingvalna i utvrđeno je da deluje antianginozno, ne toliko zbog toga što dilatira sužene koronarne arterije, već prevashodno zbog venodilatacije što dovodi do smanjenja venskog priliva u desno i levo srce, pa putem Laplaceovog zakona smanjuje zidni stres a samim tim i potrebu miokarda za kiseonikom, čime se uravnotežuju potrebe i snabdevanje miokarda kiseonikom.

Nitroglicerol (početna doza $10 \mu \mathrm{g} / \mathrm{kg}$ i.v.) uz hemodinamski monitoring treba primeniti kod bolesnika sa prisutnim anginoznim bolovima zbog perzistentne ili rekurentne ishemije, kod svih bolesnika sa AIM i srčanom insuficijencijom, kod izražene hipertenzije i velikih prednjih AIM. Intravenski nitroglicerol je od koristi kada je u AKS prisutan i koronarni vazospazam. Kontraindikacije: hipotenzija, AIM inferiorne lokalizacoije sa infarktom desne komore. Neželjene reakcije: glavobolja, hipotenzija, hipotenzija sa bradikardijom.

\section{ACE inhibitrori}

ACE inhibitori su indikovani kod bolesnika sa STEMI koji imaju disfunkciju leve komore, hipertenziju ili dijabetes (klasa preporuke I, nivo dokaza A), kao i kod bolesnika sa NSTEMI i NAP sa dijabetesom, srčanom insuficijencijom, EF < 40\% i hipertenzijom. Ukoliko nema kontraindikacija, terapiju treba započeti unutar 24 h, ili kod postizanja hemodinamske stabilnosti. Neželjene reakcije: hipotenzija, hiperkalijemija, porast kreatinina, kašalj, angioedem. Za bolesnike koji ne tolerišu ACE inhibitore, treba razmotriti primenu sartana (antagonista AT1 receptora).

\section{Statini}

Svi bolesnici sa AIM treba istog dana da dobiju jedan od statina ukoliko nisu prisutne jasne kontraindikacije (oštećenje jetre, miopatija na statine). U akutnoj fazi statini se preporučuju nezavisno od vrednosti holesterola.

\section{Antagonist aldosterona}

Treba razmotriti davanje eplerenona kod bolesnika posle AIM sa sistolnom disfunkcijom leve komore i simptomima srčane insuficijencije $(E F<40 \%)$, ukoliko je bolesnik prethodno bio na terapiji ACE inhibitorima, ako je klirens kreatinmina > od $30 \mathrm{ml} / \mathrm{min}$, a serumski $\mathrm{K}<$ od $5 \mathrm{~mm} / \mathrm{l}$.

\section{Sekundarna prevencija}

Lekove koji su propisani u bolnici treba nastaviti i dalje. Aspirin i $\beta$-blokator doživotno, a ako bolesnik ima jasne kontraindikacije za aspirin, dati klopidogrel; ACE inhibitor ako je pridružen dijabetes, srčana insuficijencija i hipertenzija. Ukoliko bolesnik ne toleriše ACE inhibitore, treba dati jedan lek iz grupe sartana. Statin primeniti dugotrajno za rigoroznu kontrolu lipida. Ukoliko bolesnik ne toleriše statin dati fibrat i omega 3 masne kiseline. Moguća je istovremena primena statina i fibrata ukoliko su povišeni trigliceridi, uz veliku opreznost od miopatije. Obavezna je izmena načina života, redukciona, hipokalorijska i hipolipemijska dijeta, aerobna fizička aktivnost uz primenu lekova. ${ }^{2}$

\section{Rizik od krvarenja tokom hirurških intervencija}

Svi bolesnici koji su na dvojnoj antitrombocitnoj terapiji imaju povećan rizik od hemoragijskih komplikacija tokom hirurških intervencija. Kod velikih hiruških intervencija sa visokim hemoragijskim rizikom, kod bolesnika koji imaju indikacije za dvojnu antitrombocitnu terapiju, prekida se klopidogrel 5-7 dana, a tikagrelor 48-72h. Kod bolesnika sa visokokim rizikom za trombozu stenta (DE stent, skorašnja $\mathrm{PCl}$ ) po prekidu klopidogrela treba dati i.v. tirofiban, a odmah posle hirurške intervencije započeti klopidogrel dozom opterećenja.

\section{Literatura:}

1. Wijns W, et al. Guidelines on myocardial revascularization: The Task Force on Myocardial Revascularization of the European Society of Cardiology (ESC) and the European Association for Cardio-Thoracic Surgery (EACTS). Eur Heart J., 2010; 31 (20): 2501-55.

2. Van de Werf F, et al. Management of acute myocardial infarction in patients presenting with persistent ST-segment elevation: the Task Force on the Management of ST-Segment Elevation Acute Myocardial Infarction of the European Society of Cardiology. Eur Heart J., 2008; 29 (23): 2909-45. 